\title{
A Epistemologia da Economia Teórica em Schumpeter
}

\author{
The Epistemology of Theoretical Economics in Schumpeter
}

MARCOS FERNANDES GONÇALVES DA SILVA*

RESUMO: O objetivo deste artigo é reconstruir os principais elementos da epistemologia instrumentalista de Schumpeter, da maneira como são expostos em seu primeiro livro publicado Das Wesen und der Hauptinhalt der theoryetischen Nationalökonomie (1908), que é o principal esforço desenvolvido pelo economista austríaco para a análise dos fundamentos da ciência econômica. Primeiramente, reconstruirei sua epistemologia instrumentalista e mostrarei a importância da mesma. Essa reconstrução é importante porque o núcleo duro da epistemologia instrumentista de Schumpeter é relativamente desconhecido. Por fim, indicarei a filiação direta da epistemologia instrumentalista de Schumpeter às ideias principais sobre a natureza da mecânica e da física em geral no final do século XIX. Essas ideias estão principalmente associadas a Ernst Mach, Henri Poincaré e Pierre Duhem, que enfrentaram o mesmo desafio de Schumpeter na economia, que é libertar a ciência (mecânica) da metafísica (cosmologia), criando uma nova visão teórica.

PALAVRAS-CHAVE: História do pensamento econômico; Schumpeter; metodologia econômica.

ABSTRACT: The objective of this paper is to reconstruct the main elements of Schumpeter's instrumentalist epistemology, in the way as they are exposed in his first published book Das Wesen und der Hauptinhalt der theoretischen Nationalökonomie (1908), which is the main effort developed by the Austrian economist for the analysis of the foundations of the economic science. Firstly, I will reconstruct his instrumentalist epistemology and I will show the importance of the same. This reconstruction is important because the hard core of Schumpeter's instrumentalist epistemology is the relatively unknown. Finally, I will indicate the direct filiation of the Schumpeter's instrumentalist epistemology to the main ideas about the nature of mechanics and of the physics in general in the end of the XIX century. These ideas are mainly associated with Ernst Mach, Henri Poincaré and Pierre Duhem who faced the same challenge of Schumpeter in economics, which is, free the science (mechanics) from metaphysics (cosmology), creating a new theory vision.

KEYWORDS: History of economic thought; Schumpeter; economic methodology. JEL Classification: B30; B31; B40.

\footnotetext{
* Fundação Getúlio Vargas de São Paulo (EAESP/FGV-SP). E-mail: mfgdasilva@gmail.com; Orcid: 00000003-4350-9918.
} 


\section{INTRODUÇÃO}

Neste artigo mostrar-se-á os principais elementos constituintes da epistemologia instrumentalista de Schumpeter, da forma como estão expostos no seu primeiro trabalho de fôlego - e primeiro livro publicado - intitulado Das Wesen und der Hauptinhalt der theoretischen Nationalökonomie - WHT (1908) (A Essência e os Princípios da Economia Teórica) ${ }^{1}$ que, sem sombra de dúvida, é o principal esforço desenvolvido pelo economista austríaco para a análise dos fundamentos da ciência econômica. Esse trabalho de Schumpeter pertence à etapa de vida que caracteriza o "jovem" Schumpeter (ver Silva, 1994)2.

Inicialmente, será feita uma reconstrução racional de sua epistemologia instrumentalista e mostrarei, dentro da economia teórica, a importância da mesma. Essa reconstrução é importante, pois o núcleo do instrumentalismo schumpeteriano para a economia teórica está no relativamente desconhecido WHT (ver Silva, 1994 e Shionoya, 1997).

Por fim, será indicada a filiação direta da epistemolologia instrumentalista schumpeteriana da economia teórica com as idéias difundidas dentro da mecânica

\footnotetext{
${ }^{1} \mathrm{O}$ título do livro pode ser traduzido das seguites formas: (i) The Nature and Essence of Theoretical Economics. Segundo Swedberg (1991b:24), essa foi a tradução feita pelo próprio Schumpeter; em português, portanto, o título seria A Natureza e a Essência da Economia Teórica; (ii) L'Essenza e i Principi dell'Economia Teorica. Esse é o título da tradução italiana de 1982; em português o título dessa edição seria A Essência e os Princípios da Economia Teórica; (iii) The Nature and Substance of Theoretical Economics é a versão dada por Shionoya (1990:189); em português o título seria, portanto, A Natureza e a Substância da Economia Teórica; (iv) Nature and Principal Content of Theoretical Economics é outra tradução feita por Harris (1951:2); em português, A Natureza e o Conteúdo Principal da Economia Teórica. O importante a ser notado é que, de qualquer forma, a palavra Wesen não possui caráter metafísico, a não ser quando aparece em textos filosóficos; em se tratando de obras científicas, podemos traduzi-la como "natureza" ou "princípio". É comum, vale notar, o uso dessa palavra em tratados de economia e negócios. Segundo o Cambridge Dictionary of German, as palavras Wesen e Hauptinhalt são consideradas sinônimos, principalmente em tratados de economia, e significam nada mais que "princípios" e "elementos" ou "conteúdo principal". O próprio Schumpeter possui um livro inacabado intitulado Das Wesen des Geldes (A Essência do Dinheiro), que pretendia ser um tratado da moeda, similar ao que Keynes elaborou; em tal livro buscar-se-ia um tratamento analítico, e não metafísico, do problema. Shionoya (1990:189) destaca ainda que Schumpeter quer ver fora do domínio da ciência as especulações metafísicas - e esse aspecto será abordado por nós. Nesse sentido, podemos aceitar todas as traduções dadas ao título do livro, desde que se tenha em mente as observações acima.

${ }^{2}$ Para maiores informações sobre a vida de Schumpeter sugerimos as seguintes fontes bibliográficas: Allen(1991a), Allen (1991b), Frisch (1951), Harberler (1951), Samuelson (1951), Smithies (1951), Swedberg (1991a) e Swedberg (1991b). Vale notar que Allen (1991a) e Allen (1991b) é a mais abrangente biografia já publicada e é recentíssima — na verdade, o livro só foi comercializado no início de 1992, juntamente com o trabalho de Swedberg (1991b). Tanto o referido trabalho de Swedberg como o de Allen foram elaborados usando como fontes entrevistas com economistas e intelectuais que conviveram com Schumpeter e os arquivos do mesmo em Harvard, só há pouco tempo atrás reorganizados. O livro de Swedberg é mais um ensaio sobre a relação de Schumpeter com a sociologia (o autor é sociólogo), no qual é explorado o conceito weberiano de "Economia Social" (Socialökonomik). Já o livro de Allen — dois extensos volumes totalizando 704 páginas - é uma biografia strito sensu, embora contenha algumas especulações sobre a natureza do trabalho teórico de Schumpeter.
} 
e da física em geral na virada do século XIX para o século XX. Essas idéias estão associadas principalmente a Ernst Mach e, em menor grau, a Henri Poincaré e Pierre Duhem.

\section{O "JOVEM" SCHUMPETER, O METHODENSTREIT E A ESSÊNCIA E OS PRINCÍPIOS FUNDAMENTAIS DA ECONOMIA TEÓRICA}

WHT teve um impacto considerável quando foi lançado. O próprio Walras teve contacto com a obra e considerou-a muito importante. Schumpeter visitou-o em 1910 e Walras, já relativamente senil, pediu que ele agradecesse ao seu pai por ter-lhe mandado um livro tão bom quanto importante. Schumpeter tentou resolver o mal-entendido explicando que ele era o autor, mas não conseguiu. $O$ fato é que era quase impossível admitir-se que alguém tão jovem (Schumpeter possuía apenas 26 anos) pudesse escrever um tratado daquele porte (ver, a esse respeito, Swedberg, 1991a:79, nº 26) ${ }^{3}$.

O livro em si é um trabalho de sistematização da ciência econômica, ou economia teórica (cujo núcleo é, para Schumpeter, a economia walrasiana) e ele pretende lidar com questões epistemológicas ao mesmo tempo em que é feita ao leitor uma exposição do conteúdo principal da disciplina. O trabalho, nos dizeres do importante biógrafo Allen (1991a:82), é "longo e repetitivo" ${ }^{4}$, embora isso não retire o mérito da obra, que é pioneira e, em determinados momentos, surpreendente. O fato é que o livro em questão representa o início da produção intelectual do "jovem" Schumpeter".

É interessante fazer algumas observações a respeito do livro mais desconhecido de Schumpeter, que, além de desconhecido, parece ter sido "esquecido" por Schumpeter. Ele próprio, quando foi para os EUA, levou todos os seus livros, in-

\footnotetext{
${ }^{3}$ Ver também, sobre essa anedota e sobre o impacto de WHT: Allen (1991a:84) e Swedberg (1991b:17, 22)

${ }^{4} \mathrm{Na}$ verdade o livro, a despeito de sua genialidade, foi escrito num tom um tanto quanto esnobe e deleitura por vezes muito cansativa. No entanto, observa Morgenstern, "[o livro] é muito prolixo, extremamente longo mas, não obstante, brilhante, vívido e absolutamente ímpar dentro da literatura em lingua alemã naquela época”. Ver Allen (1991a:85).

${ }^{5}$ Os outros livros publicados que pertencem a essa etapa da vida intelectual de Schumpeter são: (i) Epochen der Dogmen-und Methodengeschichtete - EDM (1914) (Doutrina Econômica e Método) e (ii) Theorie de wirtschaftlichen Entwicklung — TWE (1911) (Teoria do Desenvolvimento Econômico). Esse último foi publicado, na realidade, em 1911 e não 1912, como está indicado na primeira página; Augello (1991:448) coloca 1912 como a data de publicação, mas Swedberg (1991a:79,n25) revela que o livro já fora divulgado em 1911. Para todos os efeitos, utilizaremos a última data. Na verdade, esses dois livros, juntamente com WHT formam o conjunto básico de interesses investigativos de Schumpeter. Até o final de sua vida ele estudou história da ciência econômica, preocupou-se com os problemas relacionados ao desenvolvimento econômico (ciclos, crises etc.) e sempre buscou defender o estudo da economia como uma disciplina à parte, com domínio definido e com método próprio. Soma-se a essa gama de preocupações que o perseguem do início ao fim de sua vida intelectual a defesa do uso de diversas ciências auxiliares à economia, tais como a estatística, a sociologia e a história.
} 
clusive muitos artigos, menos o $\mathrm{WHT}^{6}$. No entanto, há um curioso episódio a respeito desse livro, muito interessante, e que comprova a importância do mesmo. De acordo com Allen: "A perpetuidade e importância do pensamento incorporado em Das Wesen und der Hauptinhalt são ilustradas por um evento ocorrido 37 anos após sua publicação. John R. Hicks, então um jovem economista, acompanhava as forças do General DeGaulle na libertação de Paris em 1945. Seu trabalho era encontar economistas franceses, prestar-lhes ajuda e averiguar o que eles fizeram durante a ocupação alemã. Depois de muita procura, Hicks encontrou um grupo de economistas franceses, sob a liderança de Maurice Allais (ganhador do Prêmio Nobel em 1988), que estava realizando um seminário sobre a proposição schumpeteriana [colocada em WHT] segundo a qual não existe taxa de juros em uma economia estática em equilíbrio (ver Allen, 1991a:82-5) ${ }^{7}$.

Por fim, a despeito da opinião de vários economistas de importância indiscutível sobre o conteúdo e relevância de WHT e da opinião (dúbia) do próprio Schumpeter, o fato é que qualquer obra científica tem vida independente e pública

\footnotetext{
${ }^{6} \mathrm{O}$ livro é o único que não foi traduzido para o inglês. As traduções foram feitas apenas para o japonês, 1936, com uma reimpressão em 1984, e para o italiano (1982). Mesmo em alemão o livro é difícil de ser encontrado, tendo sido inclusive um fracasso de vendas, com uma tiragem inicial que não ultrapassou os 1.000 exemplares. Cabe notar que a atitude de Schumpeter com relação ao livro envolve, pelo menos, uma certa ambigüidade. Em entrevista ao jornal do campus de Harvard (The Harvard Crimson, 11 de abril de 1944), ele refere-se desta forma ao livro: “[...] não tenho nenhuma cópia e tento me redimir deste esforço de minha juventude desde que ele foi publicado" (Ver Swedberg, 1991b:31). No entanto, podemos atribuir esse descaso com a sua primeira obra às falhas que ela possui, tanto em termos de estilo, como do ponto de vista da estrutura. Schumpeter pensou até mesmo numa segunda edição revisada. Ele começou a fazer tal revisão em 1931, quando percebeu que o livro havia virado uma peça de colecionadores (até hoje WHT é caríssimo e os japoneses detêm o maior estoque de exemplares do mesmo) (Ver Allen, 1991a:279-80). No entanto, ele nunca terminou tal trabalho.

A despeito de suas qualidades, o livro é complicado e, de fato, do ponto de vista da teoria econômica, não representava nada de novo; era apenas uma sistematização da teoria walrasiana. Schumpeter provavelmente queria ser mais conhecido por sua obra de desenvolvimento econômico (teoria da "dinâmica"), esta sim original, e não por um trabalho que se assemelha a um manual. Vale notar, não obstante, que WHT é a grande referência de Schumpeter em TWE. No primeiro capítulo da aludida obra, em que se discute os fundamentos da economia do fluxo circular ("estática"), Schumpeter sempre remete o leitor para seu primeiro trabalho. O mesmo acontece ao longo do livro e, principalmente, no capítulo $\mathrm{V}$, sobre a teoria dos juros. No total são doze citações em TWE de WHT sobre um número global de 192 (mais ou menos 6\% das citações totais, que envolvem desde comentários até referências a vários livros). Mas foi no Japão onde WHT teve um impacto importante. O livro é considerado um marco na introdução da economia moderna (walrasiana) no Japão (ver Allen, 1991a:272-3). Note-se que muitos comentaristas consideram o livro importante. Por exemplo, Samuelson afirma que: “[...] a obra mais teórica de Schumpeter foi seu primeiro livro em alemão de 1808 - Das Wesen und [der] Hauptinhal der teoretischen Nationalökonomie" (Ver Shionoya, 1997 e Shionoya, 1990:188). Na verdade, WHT era uma das poucas obras de referência e sistematização da teoria do equilíbrio geral até o lançamento de Value and Capital de J.Hicks (1939) e, precisamos lembrar, somente após à guerra torna-se mais difundido o sistema walrasiano. Em língua alemã talvez tenha sido WHT uma das únicas introduções ao tema. Ver, ainda, acerca do impacto de WHT à época de sua publicação, Swedberg (1991b:24-31) e Swedberg (1992:65-8).

${ }^{7}$ Nessa referência encontramos que Oskar Morgenstern e Wassily Leontieff reconhecem também que olivro exerceu uma grande influência intelectual sobre ambos.
} 
no mundo do conhecimento comunicável e deve ser, portanto, objeto de interpretação. O importante é destacar que essa tese de doutorado abria a estrada intelectual que o economista austríaco percorreria durante sua vida: grande parte dos problemas que ele aborda em WHT estão presentes ao longo de praticamente toda a sua obra intelectual, permeando o caminho que liga o "jovem" e o Schumpeter maduro. Dentre eles estão: (i) a diferença entre estática e dinâmica e entre estado estacionário e desenvolvimento; (ii) o caráter científico da ciência econômica; (iii) a epistemologia instrumentalista da economia teórica, o pragmatismo metodológico e os limites cognitivos da ciência econômica; (iv) a separação (demarcação) entre a economia e os outros campos de conhecimento; (v) a relação da economia com as ciências sociais (sociologia, história) e com a estatística; (vi) o papel da matemática na economia. No entanto, não se compreende a estrutura do livro nem as preocupações básicas de Schumpeter sem uma breve referência à situação na qual se encontrava a teoria econômica germânica - alemã e austríaca - no despertar do século XX.

WHT foi escrito para os economistas germânicos e pretendia ser um livro de divulgação e de esclarecimentos sobre o que Schumpeter entendia ser a fronteira da economia teórica: o sistema de equilíbrio geral estático elaborado por Walras associado com os desenvolvimentos da teoria econômica feitos pela escola austríaca (Böhn-Baverk etc). Mas, por que Schumpeter acreditava serem esses esclarecimentos necessários?

A ciência econômica estava em crise no mundo germânico na época em que ele estudou na Universidade e quando escreveu WHT. A crise surgiu devido a uma guerra de métodos que passou a ser conhecida na literatura como Methodenstreit ${ }^{8}$. Essa querela metodológica é o pano de fundo de WHT, nem tanto pelo que ela significava à época, já que Schumpeter sempre acreditou serem esses debates estéreis, mas mais pelas questões que suscitou?.

\footnotetext{
${ }^{8}$ Sobre esta querela metodológica ver, para maiores detalhes: Palgrave Dictionary of Economics (procurar o mote Methodenstreit) e Schumpeter (1954b:152-201).Vale notar que esta última referência retirada de EDM é uma boa introdução ao assunto e, por conter a interpretação de Schumpeter, é a mais interessante para os nossos propósitos aqui.

${ }^{9}$ De fato, Schumpeter acreditava que a economia clássica, em grande parte, sofria uma interferência exagerada de problemas práticos e normativos; isto é, a teoria era usada para a defesa de pontos de vista ideológicos e políticos (como o livre comércio, por exemplo). De acordo com Schumpeter, os históricos incorreram no mesmo erro que os clássicos (tão criticados por eles): submeteram a teoria às elaborações apriorísticas que pretendiam defender o protecionismo frente ao ideal do livre comércio. Para Schumpeter esse tipo de procedimento é anti-científico. Mais do que isto, puseram-se a validar o uso de um método - o método histórico - devido à adequação do mesmo aos seus a priori políticos. Essa crítica não se aplica só aos históricos, mas também a todos os economistas que justificam ou pelo menos tentam justificar o uso de uma abordagem devido a crenças políticas ou até mesmo metafísicas. Schumpeter é enfático também no que diz respeito à questão da dedução e da indução. Toda teoria envolve os dois processos. No momento da elaboração das hipóteses a experiência indutiva pode contar muito, mas a construção de teorias implica o uso da dedução; no caso da história, Schumpeter acredita que seu método seja basicamente indutivo. O problema é saber escolher a abordagem adequada para se resolver um problema específico: existem determinadas situações em que devemos adotar uma
} 


\section{Schumpeter divide o debate em três etapas:(i) uma controvérsia acerca do livre}

comércio que envolveu um confronto de filosofias políticas distintas, (ii) uma discussão acerca do papel da indução e da dedução na ciência, e (iii) a altercação entre Schmoller, de um lado, defendendo a escola histórica, e do outro, Menger, defendendo a teoria marginalista ${ }^{10}$. É importante salientar, a respeito da posição de Schumpteter, o seguinte: uma determinada abordagem (disciplina) ou uma combinação de abordagens é escolhida tendo-se em vista o problema a ser analisado (Schumpeter, 1982b:22) ${ }^{11}$ O julgamento de uma disciplina (história, economia teórica, estatística), usada para abordar um domínio de fatos, deve ser feito vis-à-vis

abordagem histórica e outras em que somos obrigados a usar a teoria, e muitas vezes saber adotar uma abordagem ou outra depende da nossa intuição, não havendo uma regra clara que determine nossa escolha (ver Schumpeter, 1982b:9-10). Contudo, para que se entenda com precisão qual é a posição de Schumpeter no Methodenstreit, é preciso, antes de mais nada, explicar o que defino como sendo o pragmatismo metodológico schumpeteriano, que no meu entender surge como solução ao debate entre métodos. Schumpeter afirma que qualquer avaliação sobre a validade de um método, seja ele histórico, teórico ou estatístico, deve estar ligada ao tipo de problema que se está estudando. Cada problema exige um método específico, caso contrário cair-se-á em debates sem valor: "Cada método possui seu domínio concreto de aplicação, e debater em termos da sua validade geral não leva a nenhum resultado: nós colocaremos sempre em evidência que uma discussão acerca de questões de método somente tem sentido em relação com a pesquisa científica prática.” (Schumpeter, 1982b:21-2)

Nesse sentido, não se pode discutir o que é peculiar à disciplina da economia teórica "nas nuvens" e também não é possível saber quando devemos usar ou combinar disciplinas diferentes, como a teoria, a estatísitca e a história, sem encararmos os problemas práticos de frente. Somente entendendo como a ciência trabalha cotidianamente com seus problemas é que poderemos, de acordo com Schumpeter, apreender suas limitações e sua natureza.

${ }^{10}$ Schumpeter, aliás, freqüentemente refere-se a esse debate como inútil e perigoso, pois esse tipo de dis-cussão pode, além de criar uma série de mal-entendidos, bloquear o progresso da ciência. O grande problema desse debate era, na realidade, a esterilidade de uma controvérsia sobre o método que não levava em consideração a utilidade prática que cada um — de cada método - pode ter para a solução de problemas específicos. O aspecto mais importante da controvérsia está, no entender de Schumpeter, ligado ao problema do uso da dedução e da indução na ciência e ao emprego dos "métodos", isto é, teoria e história. Schmoller e os "históricos" não acreditavam ser possível construir uma teoria abstrata e geral aplicada a todos os países em todos os momentos. Por outro lado, Menger advogava que se poderia construir uma teoria abstrata com "validade" independente do tempo e do lugar. Portanto, Schmoller propunha somente a possibilidade de se explicar alguns fatos singulares e, a partir de determinadas regularidades observadas, construir-se-iam algumas leis gerais, embora sempre lembrando que elas poderiam se alterar. No entanto, Menger defende o ponto de vista segundo o qual não podemos elaborar teorias apenas observando casos singulares; precisamos construir teorias abstratas que sejam usadas para deduzir algumas leis básicas, calcadas em regularidades empiricamente observadas, como ocorria na mecânica e nas ciências naturais em geral. Portanto, Schmoller é um indutivista e Menger, um dedutivista. O debate em si possuía outras motivações que não as estritamentes científicas, isto pelo menos da parte de Schmoller. A Alemanha estava passando por um processo de rápida industrialização e os históricos queriam oferecer subsídios teóricos ao protecionismo alemão. Daí advém a rejeição da teoria clássica, a qual era associada ao liberalismo inglês. Desejavam eles a construção de uma teoria econômica "alemã" para fazer frente ao que eles acreditavam ser a teoria econômica "inglesa". Schumpeter observa que os históricos confundem a teoria clássica, ou sistema clássico, com a "nova teoria" (Menger).

${ }^{11}$ Ver também Machlup (1951:95,96). 
o problema em questão (Ver Schumpeter, 1982b:10)12. É nesse sentido que afirmamos existir um pragmatismo metodológico schumpeteriano; vale notar que, no que diz respeito ao problema da escolha da disciplina, Schumpeter pode ser definido como pragmático. Isto não quer dizer que sua epistemologia da economia teórica seja pragmática. Seu pragmatismo aparece apenas quando da escolha entre disciplinas e conjuntos de disciplinas, isto é, quando optamos por uma ou outra abordagem ou por combinações entre abordagens para estudar um fenômeno. Nesse sentido, cada disciplina terá uma epistemologia própria, que também deve ser compreendida dentro dos limites gnosiológicos de cada uma das mesmas. Logo, por exemplo, a economia teórica é uma disciplina que tem uma epistemologia que lhe é particular ${ }^{13}$. Efetivamente, o que se pode concluir é o seguinte: se uma disciplina (ou um conjunto delas) consegue descrever um determinado conjunto de fenômenos, está-se gerando resultados concretos. Por exemplo, se o economista quer estudar a formação do mercado mundial, ele poderá escolher a história como o conjunto de técnicas adequado para descrever esse fenômeno, dado que ele está associado com mudanças histórico-institucionais; ou também poderá combinar economia teórica, história e estatística. Por outro lado, para estudar a formação de preços, sem nenhuma referência histórica etc., o economista deve escolher a economia teórica.

Ao observador mais desatento ou desconhecedor de WHT pode parecer que (i) Schumpeter seja um anarquista do método, onde tudo vale ou que (ii) Schumpeter mudou o seu ponto de vista metodológico ao longo da vida. A rigor, nem a primeira afirmação, nem a última, estão corretas. Em primeiro lugar, cabe salientar que Schumpeter realmente fica pessimista com relação à possibilidade de se tratar o problema dos ciclos econômicos dentro do âmbito estrito da economia teórica - que para ele sempre foi sinônimo de ciência econômica de fato. Mas a proposta de se abordar esse fenômeno com outro método é perfeitamente coerente com o que denominamos por pragmatismo metodológico schumpeteriano: se com a disciplina A não obtemos resultado — isto é, não descrevemos o fenômeno — trocamo-la por B, e assim por diante, até que seja atingido o objetivo almejado. Da mesma forma, podemos escolher entre combinações de disciplinas. Em segundo lugar, Schumpeter nunca mudou seus pontos de vista metodológico e epistemológico: a escolha entre disciplinas e conjunto de disciplinas diferentes fazia parte de

\footnotetext{
12 O que Schumpeter ora chama de método, ora de disciplina, nós denominamos conjunto de regras e técnicas (ou disciplina ou abordagem).

${ }^{13}$ A solução que Schumpeter encontra para o Methodenstreit não é, na nossa opinião, uma anarquia metodológica ou qualquer tipo de pluralismo ou tolerância metodológicos; na verdade sua solução é pragmática. Por esta razão, antes de se criticar uma abordagem de análise ou a forma de resolução de problemas de uma ou outra disciplina, deve-se levar em consideração o caráter peculiar de cada uma. Não há sentido, portanto, em discutir-se a técnica particular empregada por uma disciplina do conhecimento se não se conhece a forma que esta tem de lidar com os problemas concretos. Por outro lado, quando uma disciplina não gera resultados no sentido de descrever um determinado fenômeno ou conjunto de fenômenos, deve-se buscar uma nova disciplina, uma nova abordagem ou uma nova combinação de disciplinas.
} 
seu pragmatismo metodológico (ver Silva, 1994). Em seu artigo clássico sobre a metodologia econômica de Schumpeter, Machlup (1951) ${ }^{14}$ propõe a existência de uma tolerância metodológica schumpeteriana que, na prática, seria uma espécie de pluralismo metodológico. Nós não concordamos com essa posição. Para expor minha discordância preciso definir com maior precisão como, nesse contexto, articulam-se os conceitos de metodologia, método e epistemologia ${ }^{15}$. Cada disciplina (T), seja ela história, economia teórica ou estatística possui, para Schumpeter, um conjunto de técnicas e de regras de procedimento que lhe é particular (RTc). Cada método ou disciplina representa, portanto, um conjunto RTc usado para se abordar um conjunto de fenômenos (D) - ou domínio de fenômenos. A metodologia é um conjunto de regras (R) de escolha de disciplinas ou de conjunto de disciplinas (CTi). Logo, estabeleçam-se as seguintes Proposições Metodológicas (PM) ${ }^{16}$ : PM1: Quando eu escolho uma disciplina específica T1 para lidar com um conjunto de fenômenos D1, automaticamente estou optando por um conjunto de regras e técnicas RTc1 e irei seguir um conjunto de procedimentos. A escolha entre disciplinas Ti é a escolha entre regras e técnicas RTci. Essa escolha também pode se dar entre diversas combinações de disciplinas ou métodos CTi usados para abordar um domínio específico de fenômenos; PM2: Existe um conjunto de regras que orientam a escolha de Ti e de CTi. Esse conjunto de regras é R; PM3: O conjunto R possui um único elemento, que representa uma única regra de escolha: a regra de escolha entre disciplinas e, portanto, entre conjuntos de regras e técnicas, é a capacidade de cada um descrever um conjunto de fenômenos. $\mathrm{O}$ mesmo vale para a escolha entre conjuntos/combinações de disciplinas; PM4: R determina que o critério de escolha entre disciplinas seja prático; o mesmo vale para a escolha entre os conjuntos-combinações de disciplinas. De acordo com R, a escolha, seja ela entre disciplinas ou entre combinações das mesmas, deve seguir o critério prático da resolução de problemas $^{17}$.

\footnotetext{
14 Este artigo e o artigo de Shionoya (1990) são os únicos trabalhos publicados sobre o assunto. Issorevela que, de fato, a contribuição de Schumpeter à epistemologia "não recebeu a atenção que merece". Ver Shionoya (1990:187). Note-se que tal negligência dentro da história do pensamento econômico foi grave. Como mostra Shionoya (1990:188), isso pode ter ocorrido devido ao fato de WHT nunca ter sido traduzido para outras línguas a não ser, como já falamos, o japonês (1936, reimpressão em 1984) e o italiano (1982).

${ }^{15} \mathrm{O}$ próprio Schumpeter não se preocupa muito em definir os conceitos que usa; deriva desse fato muitas das confusões com as quais os leitores se defrontam ao longo de sua obra.

${ }^{16}$ Usaremos a abreviação PM para as proposições metodológicas. Todas as outras abreviações seguirãoo mesmo padrão.

${ }^{17}$ Machlup parece confundir a tolerância de Schumpeter quando da escolha entre disciplinas e conjuntos de disciplinas e a escolha de diversos "métodos" dentro da economia teórica, como se a economia teórica ora fosse teórica, ora histórica, ora estatística. O meu argumento é algo distinto. O pragmatismo metodológico schumpeteriano, tal qual o defini, arbitra com tolerância a escolha entre a história, a estatística e a economia e entre conjuntos combinados das mesmas; Machlup, ao contrário, parece querer mostrar que Schumpeter permite que a história se misture com a economia teórica, como se ambos não possuíssem uma identidade definida. Cabe observar, contudo, o papel importante dado à
} 
Mostraremos, a seguir, que Schumpeter defende uma epistemologia instrumentalista para a economia teórica ${ }^{18}$.

\title{
3. A ESSÊNCIA E OS PRINCÍPIOS FUNDAMENTAIS DA ECONOMIA TEÓRICA: O INSTRUMENTALISMO SCHUMPETERIANO
}

\author{
Antes de apresentar a definição de teoria, explorar-se-á o conceito de economia \\ teórica que Schumpeter apresenta em WHT. Tal procedimento pode parecer con-
}

teoria por Schumpeter. Salvo algumas raras exceções, a teoria sempre deve estar presente dentro dos conjuntos de disciplinas que serão objeto de escolha pragmática. O economista não se define, para Schumpeter, como um estatísitco ou como um historiador. Ele é, antes de mais nada, um teórico que, por vezes, precisa recorrer a outros métodos para abordar alguns problemas. Um dos esforços básicos de Schumpeter em WHT está justamente em demonstrar a relevância da economia teórica ou simplesmente da teoria para a formação da economia científica e do economista.

$\mathrm{Na}$ introdução ao WHT ele faz essa distinção entre as disciplinas que o economista pode usar, seguindo o critério pragmático, reconstruído racionalmente por nós: por exemplo, o método histórico pode ser, em alguns momentos, mais eficiente na busca de soluções de problemas do que a economia teórica, embora esta seja o núcleo da formação do economista teórico.

No entanto, uma vez feita essa distinção, a preocupação do economista austríaco passa a ser outra: definir a essência e os princípios da economia teórica. Ele irá definir os limites gnosiológicos da disciplina ou abordagem em questão e, portanto, estará buscando construir uma epistemologia da economia teórica. Schumpeter mantém sua posição segundo a qual não se pode entender a natureza do trabalho científico, agora em economia teórica, abstraindo-se a forma concreta de elaboração das mesmas. $\mathrm{O}$ que foi afirmado para a análise do pragmatismo metodológico, portanto, continua valendo para a análise da natureza do conhecimento fornecido pela economia teórica. Não se deve negligenciar o estudo da teoria para se definir sua estrutura epistemológica. Por essa razão, não tem sentido um manual de economia teórica que possua como capítulo inicial tópicos de discussão epistemológicos (ver Schumpeter, 1982b:10, 421-97). Dado um problema (representado por um conjunto de fenômenos que se quer analisar), deve-se buscar a solução do mesmo, combinando-se disciplinas e escolhendo-se entre essas combinações ou, simplesmente, entre disciplinas singulares. A conclusão é a seguinte: Schumpeter, mais que propor uma certa "tolerância" ou pluralismo metodológico, define uma regra básica de escolha entre disciplinas e métodos que o classificam, nesse contexto, como um pragmático. É preferível usar o conceito "pragmatismo metodológico" pois, embora envolva a idéia de tolerância, como quer Machlup, ele se diferencia da idéia defendida pelo economista.

18 Precisamos alertar que Schumpeter, ao longo de WHT, usa os seguintes conceitos como sinônimos: (i) economia teórica, (ii) teoria estática, (iii) teoria econômica, (iv) ciência econômica, (v) economia, (vi) economia pura, (vii) economia exata. Veremos que a ciência é definida, para ele, a partir do conceito de teoria: é a própria estrutura da teoria (walrasiana) que fornece um conceito de ciência econômica. Ciência econômica, teoria econômica e teoria lato sensu são, portanto, tratados como sinônimos. Como em WHT a teoria econômica limita-se à teoria estática walrasiana, a teoria estática passa a ser a mesma coisa que teoria econômica. Schumpeter acredita que a economia teórica é, do ponto de vista epistemológico, igual à mecânica — isso também veremos mais abaixo. Dessa forma, pode-se usar como substituto para economia teórica os conceitos de economia exata (exata porque leva a resultados nãotriviais) e economia pura (pura porque definida independentemente das outras ciências), sempre lembrando que era próprio do período dar-se essas denominações (pura, exata) às ciências naturais. Para todos os efeitos, todos os conceitos de (i) a (vii) são sinônimos em WHT. Já em TWE a economia teórica, a teoria pura, é ampliada, em seus limites descritivos, para a teoria do desenvolvimento econômico. Esse esclarecimento é importante pois Schumpeter, infelizmente, somente adverte o leitor com relação ao uso não muito ordenado que faz desses conceitos nas últimas páginas de WHT. Ver, por exemplo, Schumpeter (1982:461). 
trariar o bom senso, mas na realidade apenas estou respeitando a própria estrutura do livro e o ponto de vista do autor, que sustenta a necessidade de se conhecer a teoria em questão antes de se fazer qualquer afirmação sobre sua natureza epistemológica. Deve-se salientar que Schumpeter trabalha com a teoria estática, representada pelo sistema walrasiano, como núcleo ou punctun saliens da economia teórica; em certo sentido, teoria, economia teórica e sistema de equilíbrio geral se confundem.

Schumpeter afirma que o fundamento exato da economia é o conceito de troca: "Pois então, como fundamento da nossa disciplina está a noção de que todas essas quantidades [as quantidades de determinados bens], que chamaremos brevemente "quantidades econômicas", travam entre si relações tais que a mudança de uma delas trás como consequência a mudança das outras." (Schumpeter, 1982:37).

Logo, elabore-se a seguite Proposição Teórica 1 (PT1): A economia teórica lida com um sistema de quantidades. Essas quantidades são denominadas "quantidades econômicas" e representam determinados quanta de bens e serviços. Essas quantidades estão em relação de mútua dependência. A seguir, pode-se derivar a que tipo de resultado tal sistema de quantidades conduz: "Se agora descobrimos que as quantidades estão numa relação tal que ao valor de uma ou de algumas corresponde um e um só valor das outras, chamaremos o sistema de univocamente determinado[...]. Chamaremos essa situação "estado de equilíbrio" e as quantidades particulares desse estado de normais ou naturais." (Shumpeter, Idem). Ao conceito de economia como sistema de quantidades soma-se agora a noção de "estado de equilíbrio" ou simplesmente "equilíbrio". Pode-se enunciar outra proposição. PT2: O sistema de quantidades produz uma solução única; quando o sistema determina essa solução, podese dizer que o equilíbrio foi atingido. PT1 e PT2 definem (i) o domínio da disciplina — a relação entre quantidades econômicas - e (ii) o tipo de solução que o sistema determina - o equilíbrio entre as quantidades econômicas. É necessário, então, mostrar como esses fatores se relacionam para que obtenhamos uma "explicação" econômica dos fenômenos: "Dado qualquer estado do sistema econômico, o nosso objetivo é agora o de derivar aquelas trocas de quantidade que se verificariam no instante posterior se não acontecesse nenhum imprevisto. Nós denominamos esse procedimento de "explicação" e será realizado mediante a descrição das relações de dependência, de tal forma que possamos definir o nosso objetivo como a descrição do nosso sistema e das suas tendências de movimento. Caso isso seja possível de forma unívoca sem se referir, ao longo desse procedimento, a princípios materiais de outras diciplinas, deriva-se uma ciência da economia definida em torno de si mesma. Denominamos as proposições que dão lugar a tais descrições de "leis econômicas" e estas são de uma importância notável. O nosso complexo forma a ciência da economia teórica ou pura."(Schumpeter, 1982b:38) ${ }^{19}$.

\footnotetext{
${ }^{19}$ Existe um elemento importante de toda essa formulação que Schumpeter apresenta e que não é notado pelos poucos comentadores dos aspectos epistemológicos de WHT, como Machlup (1951) e Shionoya
} 
Schumpeter define a função da teoria ou economia teórica como segue: "Indicamos como objetivo da nossa ciência a descrição das relações de dependência entre os elementos do nosso sistema, com o fito de poder sucessivamente simplificar as diversas condições, e dissemos que, falando de explicação científica dos fenômenos dos quais a economia se ocupa, não entendemos nada além de tal descrição. Por isso, os termos 'explicação' e 'descrição' são para nós, em geral, sinônimos; em outras palavras, nós desejamos e podemos contribuir à comprensão dos fatos econômicos não fazendo outra coisa se não os descrever" (Schumpeter, 1982b:44). Não obstante o qualificativo "em geral", Schumpeter fundamenta de fato a noção de exlicação na idéia de descrição. Do acima dito enunciarei uma Proposição Epistemológica (PE) e uma Definição (D) que são da máxima importância para a construção do instrumentalismo epistemológico schumpeteriano. PE1: Explicação é descrição. Isso significa que explicar uma variação de preço resume-se simplesmente na descrição dessa variação. Logo, pode-se enunciar a seguinte definição D1: Leis econômicas são as proposições que formalizam essas descrições; são a forma literal ou matemática por meio da qual a explicação é transmitida em enunciados. Por exemplo, quando eu falo que um aumento de preço de um bem específico está ligado a um aumento da demanda por esse bem coeteris paribus, estou enunciando uma lei que transmite, por meio de palavras, uma descrição. Entretanto, eu falo que um fenômeno específico (no exemplo acima, aumento do preço de um bem) está ligado a um outro fenômeno (aumento da demanda). Que tipo de ligação é essa?

(1990). Schumpeter observa que (i) a construção de um sistema de quantidades e (ii) a obtenção de uma solução unívoca é importante para o fundamento da economia teórica ou economia pura. Segundo ele: “A determinação unívoca de um sistema de quantidades é um fato científico da máxima importância enquanto significa que, quando estamos de posse de certos dados, recolhemos também todos os elementos necessários para 'entender' as dimensões de tais quantidades e seus movimentos” (Schumpeter, 1982b:41). Note-se nessa passagem a união do conceito de equilíbrio e de solução unívoca com o conceito de descrição (quando Schumpeter fala em "entender" ele está referindo-se à descrição e observese que ele coloca a palavra entender entre aspas). Schumpeter chega a dizer que a determinação unívoca de um sistema de quantidades, isto é, a existência do equilíbrio, é "a pedra angular de uma construção científica" (Schumpeter, 1982b:42). Schumpeter define o equilíbrio da seguinte forma: "Equilíbrio é uma expressão não muito feliz para designar-se uma condição na qual, contanto que não intervenha de fora algum elemento de disturbância, não existe qualquer tendência de mudança” (Schumpeter, Idem). A definição de um estado de equilíbrio é o primeiro passo para a descrição dos movimentos das quantidades econômicas, pois ele define uma situação inicial de interrelação entre as quantidades (preços e quantidades de bens). Tal definição não é uma hipótese ou mesmo um simples axioma; na verdade, o equilíbrio é condição necessária para que se obtenha uma descrição de preços e quantidades não trivial. Quando o sistema está em equilíbrio existe uma e somente uma solução para o sistema de quantidades. Uma vez determinado esse estado pode-se fazer um experimento mental supondo-se que se altere, num momento do tempo posterior, uma dada quantidade - por exemplo, o preço de um bem — dada a condição coeteris paribus. Com um novo estado de equilíbrio, pode-se explicar as variações ocorridas descrevendo-as. A explicação é somente a descrição — e nada mais — dos movimentos observados das quantidades especificadas no modelo. Quero salientar que sem essa ligação entre o conceito de equilíbrio e o conceito de explicação, fica muito difícil perceber-se a relação entre explicação e descrição, que são, de fato, sinônimos. Sobre essa identidade entre explicação e descrição Schumpeter é mais enfático quando define o objetivo da economia teórica. A partir daí poderemos começar a reconstruir a epistemologia schumpeteriana. 
Shumpeter afirma que: “[...] a explicação oferecida pela nossa teoria é, portanto, uma descrição de relações funcionais entre os elementos do nosso sistema mediante fórmulas que sejam as mais breves [...] possíveis. Chamamos tais formulações de 'leis'" (Schumpeter, 1982b:44). Portanto, pode-se elaborar duas proposições a respeito do que está posto acima. PE2: A explicação é a descrição estabelecida por meio de relações entre fenômenos; PE3, essa descrição é formulada como lei e esta deve fornecê-la da forma mais breve possível, isto é, da forma mais econômica possível. Passarei a denominar PE3 de Princípio da Economia de Pensamento-PEP ${ }^{20}$. Considere, desta forma, as seguintes proposições. PE4: Existe um critério de demarcação entre ciência e metafísica; ambas são distintas; PE5:O critério de demarcação entre economia teórica e metafísica é o seguinte: a ciência trata de estabelecer relações funcionais entre fenômenos observados pela experiência da vida prática, não buscando causas para os fenômenos. Já a metafísica procura as causas que residem atrás dos fenômenos. Denominarei PE5 de Critério de Demarcação-CD.

Para se ter uma visão completa do que Schumpeter denomina por economia teórica, preciso definir mais alguns conceitos. Em WHT encontra-se a seguinte definição gnosiológica de economia teórica (ou pura): D3: "A mais correta definição gnosiológica da economia pura seria, portanto, a seguinte: ela deve reduzir as quantidades de bens que estão sob a posse de cada um dos sujeitos econômicos em

${ }^{20}$ O que se pretende quando da definição de uma lei é a descrição dos fenômenos e não a busca de suas causas. Nesse ponto Schumpeter é enfático: “[...] não deverão ser investigadas importantes relações causais, mas serão descritas somente circunstâncias claramente visíveis" (Schumpeter, 1982b:49; as “importantes relações causais" ficariam para a explicação filosófica, metafísica ou essencialista). E não há sentido em crer que o objetivo central da ciência seja a busca de causas (embora seja plausível supor que existam "importantes relações causais”; o problema é que essas relações estão fora do domínio da economia teórica enquanto ciência). Schumpeter afirma: “[...] caso porém, se observarem as coisas com mais proximidade, convenceremo-nos facilmente de que o núcleo de cada teoria, o que ela verdadeiramente diz, é sempre e somente uma afirmação sobre relações funcionais existentes entre algumas grandezas" (Schumpeter, 1982b:44).

Essa preocupação com a diferença entre explicação causal e explicação funcional (ou simplesmente, descrição) pode parecer desnecessária. No entanto, pode-se afirmar que a distinção entre causa e função e a opção de Schumpeter pela última é um dos pilares da sua epistemologia instrumentalista. Com a definição de explicação como descrição - em contraposição à definição de explicação como explicação causal - evita-se a obscuridade da metafísica, ao modo de Mach, Poincaré e Duhem. O economista austríaco quer demarcar a fronteira entre a economia e a metafísica; a economia somente trata de estabelecer relações funcionais entre entidades visíveis, isto é, empiricamente perceptíveis. O domínio da economia teórica é representado por esses fenômenos. Defina-se, portanto, teoria, do ponto de vista funcional, usando as palavras do próprio Schumpeter. D2: “[...] a teoria oferece-nos exclusivamente descrições, isto é, descrições de certas relações funcionais” (Schumpeter, 1982b:52). Com a delimitação do domínio da economia teórica aos fenômenos e com a aceitação da explicação funcional, Schumpeter coloca a metafísica "para fora" da economia teórica. A esse respeito, afirma Schumpeter que, primeiro, “[...] não se deve esquecer que aqui nos baseamos, como para as nossas considerações precedentes, sobre o trabalho científico prático, sobre a experiência resultante dele, sobre seus objetivos científicos concretos, e não sobre princípios primeiros genéricos ou sobre especulações metafísicas” (Schumpeter, 1982b:422). Segundo: "Em geral a teleologia e a ciência são antípodas e o serão sempre [...]" (Schumpeter, 1982b:134). 
qualquer instante, àquelas quantidades que os mesmos sujeitos possuíam num 'instante' anterior e isso deve ser feito da forma mais rápida, que é a das hipóteses formais”(Schumpeter, 1982b:124). Dessa afirmação são inferidas mais duas proposições epistemológicas: PE6: Do ponto de vista gnosiológico, isto é, em termos de valor de conhecimento, a teoria deve descrever o movimento ocorrido nas quantidades econômicas da forma mais breve possível. O princípio PEP deve ser respeitado: explicação é descrição e esta deve ser econômica em termos de pensamento. Logo, pode-se afirmar mais uma proposição. PE7: A hipótese formal é o meio utilizado para se atingir uma descrição que implique uma economia de pensamento ${ }^{21}$.

Com base nessas afirmações pode-se elaborar mais duas proposições epistemológicas. PE8: As hipóteses sustentam a teoria, o esquema descritivo. PE9: As hipóteses são, em certo sentido, pura criação do nosso arbítrio. Porém, se de um lado as hipóteses são criação do arbítrio, por outro, elas têm uma contrapartida com os fatos, com os fenômenos: a elaboração de hipóteses é permeada pela experiência do agente cognoscente: “[...] na construção do nosso sistema procedemos arbitrariamente, mas também racionalmente esboçando as hipóteses sempre em consideração aos fatos. Para usar a expressão de um pensador profundo: um alfaiate produz um paletó e este é um produto do seu arbítrio na medida em que lhe seria permitido talhá-lo de uma forma diferente; não obstante esse fato, esperamos que ele caia bem e que não nos surpeeendamos com isso, quando acontecer, dado que foi feito sob medida" ${ }^{22}$. Essa figura retirada de Poincaré é muito feliz, pois

${ }^{21}$ É necessário, neste sentido, explorar-se o conceito de hipótese, sem o qual não se completa a análise de toda a estrutura epistemológica da economia teórica. Schumpeter afirma que, (i) “[...] a economia pura estática não é outra coisa senão um quadro abstrato relativo a determinados fatos econômicos, um esquema que deve servir à sua descrição; tal esquema repousa sobre determinadas hipóteses e é por isso uma criação do nosso arbítrio, da mesma forma que o é em cada uma das outras ciências exatas" e (ii) "[...] as hipóteses que nós fazemos são em si mesmas um tanto arbitrárias, quanto o são as definições”. Schumpeter (1982b:50).

${ }^{22}$ Schumpeter (1982b:424). O "pensador profundo" ao qual Schumpeter se refere sem citar é Poincaré. Ele voltará a usar essa metáfora no seu grande livro de história da análise econômica. No entanto, desta vez, ele citará a fonte. (Ver Schumpeter 1954:15, $\mathrm{n}^{\circ}$ 2). Discordo de Swedberg, que em sua recente biografia de Schumpeter parece ter feito uma pequena confusão. Discorrendo sobre o tema acima, ele afirma: "O economista, afirma Schumpeter, faz uma simplificação ao fazer assunções, abstraindo e isolando determinadas carcterísticas num fenômeno. Ao olho sem treino, isto pode significar que o resultado de toda esta atividade tem pouco a ver com a realidade. Mas não é este o caso; com algumas poucas pinceladas o economista de fato criou seu próprio quadro da realidade. Este quadro não é idêntico à realidade, mas ele captura a sua essência e é isto que importa. Para usar uma das metáforas preferidas de Schumpeter, um teorema econômico adapata-se à realidade da mesma forma que um paletó bem feito [ajustado] adapta-se ao corpo de um consumidor." (Swedberg, 1991b:26-27). Minhas divergências são: (i) não é sobre teoremas que Schumpeter fala, mas sim sobre hipóteses, embora a afirmação de Poincaré possa ser estendida aos teoremas e à teoria como um todo (a teoria pode ser interpretada como uma grande hipótese que, espera-se, seja adaptada aos fatos; (ii) a afirmação final é de Poincaré e não de Schumpeter e essa observação é importante para que se compreenda o sentido da mesma; (iii) o sentido da mesma está ligado ao convencionalismo e ao instrumentalismo e, neste caso, Poincaré nunca diria que uma hipótese, ou um teorema, ou uma teoria capturam a essência da realidade; o problema dele é exatamente mostrar o contrário, isto é, que a teoria em geral é um aparato descritivo 
mostra exatamente a natureza de uma hipótese - incluindo-se aí os axiomas. Sempre teremos hipóteses mais ou menos abstratas, mas é importante observar que sempre elas apresentarão esse duplo caráter, isto é, sempre serão um criação arbitrária e sempre terão como referência os fenômenos. Note-se que essa visão de Schumpeter acerca das hipóteses e de sua natureza o aproxima de Poincaré e de seu convencionalismo, pelo menos nesse aspecto. Saliente-se, no entanto, que o ideal para a teoria é conseguir adaptar-se a um número crescente de fenômenos. Mais uma vez, Schumpeter lança mão da metáfora de Poincaré: "Da mesma forma que o alfaiate possui, por esta razão [garantir encomendas de imprevisto que não são feitas sob medida], um estoque de paletós prontos, esperamos que a nossa mercadoria adapte-se sempre a um número crescente de clientes. Em geral as nossas expectativas são satisfeitas; o alfaiate diz que seus paletós adaptam-se, nós falamos que os nossos enunciados são 'geralmente válidos'” (Schumpeter, 1982b:424).

A mesma observação vale para as leis ou os teoremas derivados das hipóteses e axiomas. Isto é, espera-se construir uma teoria suficientemente generalizante de tal forma que ela se adapte a um número crescente de fenômenos. Antes de definir o que são teoremas, preciso fazer as seguintes afirmações, que pontuam as proposições de Schumpeter. PE10: As hipóteses são elaboradas tendo-se em conta os fenômenos. Complementando PE9 com PE10, afirma-se D4: Hipóteses são enunciados utilizados na construção da teoria e, ao mesmo tempo que possuem uma relação com os fenômenos, são uma criação arbitrária do agente cientista. Posto isto, pode-se elaborar a seguinte proposição PE11: As hipóteses não são julgadas pelo seu suposto valor cognitivo, mas sim pela capacidade de gerar uma descrição eficiente, que simplifica o trabalho mental. Elas não são nem falsas, nem verdadeiras; elas se adaptam melhor ou pior aos fatos. $\mathrm{O}$ mesmo vale para as teorias, que podem ser encaradas como um conjunto ordenado de hipóteses e de leis derivadas dedutivamente (teoremas). Portanto, segundo a minha reconstrução dos argumentos schumpeterianos, a teoria é formada por um conjunto de hipóteses e de teoremas derivados das mesmas. Mas, o que são teoremas? Segundo Schumpeter, os teoremas são derivações lógicas feitas a partir de um conjunto de hipóteses: “[...] existe um sistema de conceitos definidos de qualquer modo que permite, mediante as regras da lógica, completar uma derivação de determinados juízos de partida, contra os quais, do ponto de vista dessas regras e quando elas não são contraditas, não se pode fazer nenhuma objeção" (Schumpeter, 1982b:426) ${ }^{23}$.

Pode-se definir teorema como segue, isto é, D5: Teoremas são proposições derivadas de determinadas hipóteses iniciais mediante a aplicação de regras da

e convencional; (iv) Schumpeter usa a metáfora do alfaiate para enfrentar a mesma questão de Poincaré, qual seja: as hipóteses e as teorias em geral — que são derivadas das primeiras - têm uma característica de arbitrariedade e, ao mesmo tempo, são elaboradas vis-à-vis os fatos (os fenômenos) observados empiricamente e a eles devem se adaptar. Elas não têm nada a ver com a essência da realidade. Schumpeter, como Poincaré, Mach e Duhem, quer livrar a ciência da metafísica e ele não busca capturar nenhuma essência (como a essência do valor, por exemplo).

${ }^{23}$ Schumpeter (1982b:426). 
lógica. Então, é permitido afirmar que a "validade" da teoria, do ponto de vista lógico, independe dos fenômenos. Ela é, neste sentido, uma construção abstrata: "Para dizer a verdade, existe um aspecto com relação ao qual pode-se dizer que a teoria é válida de forma absoluta, infalível, e até independente da observação dos fatos. Essa posição somente pode se sustentar do ponto de vista da sua 'coerência lógica" " ${ }^{4}$. Neste ponto deve-se explorar com maior profundidade a natureza do critério de demarcação entre ciência e não-ciência e em especial entre a economia teórica e a metafísica. $\mathrm{Na}$ minha opinião, Schumpeter é um verificacionista, pois as teorias, embora sejam estruturas arbitrárias e tenham uma "validade" estritamente lógica num determinado sentido, devem descrever fatos econômicos, devem adaptar-se aos fenômenos econômicos observáveis. Essa adaptação, como em Mach, Poincaré e Duhem, não implica na refutação ou rejeição de teorias, mas simplesmente na adaptação melhor ou pior das mesmas aos fatos. Os cientistas, no caso os economistas, criam suas teorias e procuram adaptá-las aos fatos e este processo de adaptação pode envolver reelaborações sucessivas das mesmas até que se atinja um grau desejável de descrição eficiente dos fatos ${ }^{25}$.

Posto isso, colocam-se três enunciados importantes, com base em afirmações anteriores e no que logo acima está dito: (i) Critério de Escolha de Hipóteses (CEH); (ii) Critério de escolha de Teorias (CET); (iii) Critério de Demarcação Verificacionista (CDV).

CEH: Dado um conjunto de hipóteses, deve-se escolher a que mais atenda ao critério de economia de pensamento e que crie, portanto, juntamente com outras hipóteses, uma teoria que descreva da forma mais geral, simples e breve possível os fenômenos do domínio econômico. As hipóteses não são escolhidas de acordo com seu suposto valor de conhecimento, isto porque elas não são nem falsas, nem verdadeiras.

\footnotetext{
${ }^{24}$ Schumpeter (Idem).

${ }^{25}$ Ampliando a metáfora do alfaiate que Schumpeter empresta à Poincaré, os economistas teóricos são como costureiros que fazem paletós masculinos em larga escala - pret-à-porter - esperando, é claro, que esses paletós se ajustem "na medida" para a maior parte do universo de possíveis compradores, levando em consideração, é claro, as proporções padronizadas ergonômicas de cada grupo de clientes. Mesmo um costureiro avant-garde procurará fazer um paletó que se adapte ao corpo dos clientes (embora muitas vezes não se adapte aos gostos dos mesmos!). A ciência é, em grande parte, construída pelos cientistas que realizam um trabalho contínuo de adaptação das teorias aos fatos, mas também existem cientistas que criam grandes inovações - e estes seriam equivalentes aos costureiros avant-garde. Todavia, essas inovações teóricas devem ser passíveis de adaptação aos fatos e devem ser reformadas sempre que tal adaptação não ocorra de forma eficiente. Como o costureiro, o cientista não se livra simplesmente dos modelos que não se adaptaram bem, mas procuram, calcados na indução e na experiência, desenvolver as estruturas já existentes de forma a criar uma adaptação mais eficiente das mesmas. Note-se que não existe aqui um critério de demarcação calcado na lógica, como o de Popper, por exemplo. O critério de demarcação apenas refere-se à possibilidade de o conhecimento científico ter (i) uma relação com o empírico ou com os fatos empiricamente observáveis e (ii) uma relação de adaptabilidade desejada com os mesmos fatos. Essa adaptabilidade está ligada à idéia de que não existe experimento crucial e de que, na verdade, há apenas a busca de uma melhor descrição, isto é, classificação e arquivamento dos fenômenos.
} 
Defina-se, do ponto de vista estrutural, uma teoria como um conjunto de hipóteses e teoremas derivados das mesmas: $\mathrm{T}=\{\mathrm{Hi}, \mathrm{Ti}\}$, onde Hi representa as hipóteses e Ti os teoremas. Assim sendo, as teorias devem propiciar, com o uso de hipóteses adequadas e da dedução, uma descrição rápida, simples e geral dos fenômenos econômicos. Pode-se enunciar o seguinte Critério de Escolha de Teorias (CET): Dado um conjunto de teorias, deve-se escolher a que mais atenda ao critério de economia de pensamento e que descreva, portanto, da forma mais geral, simples e rápida possível os fenômenos do domínio econômico. Como no caso das hipóteses, as teorias não são escolhidas de acordo com seu suposto valor cognitivo; elas não são verdadeiras, nem falsas.

Por fim, tanto as teorias como as hipóteses devem ser passíveis de adaptação aos fatos, já que o único objetivo da ciência é buscar a descrição e não a explicação dos fenômenos, tarefa relegada à metafísica. Enuncie-se, portanto, o seguinte critério de demarcação verificacionista CDV: a economia teórica descreve fatos econômicos e, neste sentido, ela constitui-se de conhecimento sobre o mundo das coisas observáveis e deve apenas gerar descrições que se adaptem às mesmas. As teorias, como não são nem falsas, nem verdadeiras, apenas podem funcionar como instrumentos eficientes para o arquivamento e classificação de fatos. As teorias são apenas aparatos descritivos, pois não buscam a explicação dos fenômenos. No entanto, a história (história econômica e institucional) também é descritiva. Qual seria então, a diferença entre a história e a economia teórica?

Há uma diferença entre a descrição fornecida pela história e a descrição teórica ${ }^{26}$ : "A diferença reside nisto. A descrição histórica limita-se a uma catalogação dos fatos. A teoria efetua neles uma transformação, mas em nenhum caso perse-

\footnotetext{
${ }^{26}$ Quando Schumpeter fala em descrição teórica ele usa o termo Beschreibung [descrição]; para a descrição histórica o termo é Deskription [descrição]. (Ver Swedberg 1991b:254n26). Este ponto é importante pois Schumpeter quer livrar-se de um problema gerado pelo Methodenstreit. A história tem seu papel no conhecimento, no entanto ela possui fundamentos epistemológicos distintos dos da economia teórica. Schumpeter resolveu, como vimos, o problema da escolha da disciplina, adotando o que resolvemos denominar de "pragmatismo metodológico". Deve-se escolher a abordagem ou o conjunto de abordagens que seja mais eficiente em termos de resolução de problemas. Todavia, à época em que escreveu WHT alguns acadêmicos ainda não compreendiam essa distinção que o preocupava tanto. A história - ou a história econômica, como queiram - possui sua própria estratégia de lidar com fatos e tem limitações cognitivas que lhe são inerentes; o mesmo vale para a economia teórica. Era trivial, mas Schumpeter deveria insistir nesse ponto, pois a academia germânica não estava de fato familiarizada com as características mais básicas da economia pura representada pelo sistema walrasiano. A este respeito Schumpeter declara: "A questão é colocada toda vez no sentido de perguntar-se se a teoria é dedutiva ou indutiva: a resposta é favorável à primeira alternativa [...]". Essa afirmação permite enunciar o seguinte PE12: A teoria, ou a economia teórica, é dedutiva.

De tal afirmação, no entanto, não se infere que a indução, no sentido de indução empírica, não seja importante para a construção e para a reelaboração de teorias, buscando uma melhor adaptabilidade aos fatos. No entanto, a teoria em si é uma estrutura calcada na dedução. Por outro lado, a história lida com fatos singulares e não objetiva a formulação de leis com "validade geral”. Já a teoria busca elaborar teoremas que traduzam, em termos racionais, a regularidade de alguns fenômenos: a teoria é uma abstração generalizante e pretende ser uma síntese; suas hipóteses são elaboradas de tal forma a alcançar essa generalização descritiva da forma mais econômica possível.
} 
guindo um objetivo particularmente longínquo ou misterioso, mas exclusivamente para uma melhor síntese dos mesmos. Ela constitui um esquema que tem o objetivo de explicar brevemente a incalculável quantidade dos fatos e de atingir da maneira mais rápida e mais completa possível aquele objetivo o qual denomino por discernimento" 27 .

Note-se que aqui Schumpeter persegue a unidade, a completude e a simplicidade, como Poincaré e Duhem. O que não fica claro é se é possível combinar-se a unidade com a simplicidade, problema, aliás, como vimos anteriormente, enfrentado por Poincaré. De afirmações anteriores e do que acima está posto podemos fazer as seguintes proposições. PE13: A descrição histórica limita-se à descrição ou catalogação dos fenômenos; PE14: A descrição teórica cataloga os fenômenos, mas busca conferir um discernimento deles, estabelecendo relações funcionais entre eles; essas relações geram, da forma mais econômica possível, enunciados descritivos, simples e gerais. Uma vez resumidos, na forma de definições e proposições, alguns aspectos fundamentais da epistemologia do "jovem" Schumpeter em WHT, discutiremos um exemplo, retirado do mesmo livro, para ilustar a visão de instrumentalismo que ele aplica à economia teórica.

Schumpeter é considerado o primeiro cientista social a usar o conceito "individualismo metodológico" 28 . Grande parte de sua preocupação estava direcionada para a diferenciação entre individualismo político (associado ao liberalismo) e individualismo metodológico, que para ele apenas era sinônimo de atomismo e não possuia qualquer valor ético, político ou cognitivo. A escola histórica alemã identificava o individualismo metodológico com o liberalismo anglo-saxão e, portanto, com o individualismo político. Esse tipo de confusão, acreditava Schumpeter, surgia porque não se considerava o fato de que o individualismo metodológico é uma hipótese sem valor cognitivo ${ }^{29}$. Podemos conceituar o individualismo metodológico como uma hipótese que explica os movimentos no processo econômico a partir do movimento dos "átomos" ou unidades que compõem esse processo. Esses átomos ou unidades são denominados "indivíduos”; “[o individualismo metodológico]

\footnotetext{
${ }^{27}$ Schumpeter (1982b:47).

${ }^{28}$ Ver Machlup (1951:100) e Shionoya (1990:202). Isso não quer dizer que Schumpeter tenha sido o primeiro a discutir o tema. Na verdade, a informação que se tem diz que ele foi o primeiro a cunhar o conceito. Existem outros dois artigos nos quais o tema é discutido que só recentemente foram publicados, pois estavam nos arquivos de Schumpeter em Harvard. Ver Schumpeter (1991c) e Schumpeter (1991b). Na primeira referência encontramos: "Em alguns problemas de sociologia ou da vida política etc., não temos nenhuma ecolha a não ser partir da totalidade social. Em outros casos, como o fenômeno do mercado [...] não existe outra escolha fora começar pelo individual.” Schumpeter (1991c:272).

${ }^{29} \mathrm{O}$ mesmo problema aparecia quando da escolha entre o individualismo metodológico e o coletivismometodológico (explicação da totalidade dos fenômenos a partir de grupos sociais tais como classes etc.). A escolha entre as duas abordagens deve levar em consideração a capacidade de cada uma descrever melhor os fenômenos; a opção por uma ou por outra não pode estar ligada a qualquer tipo de avaliação moral, política ou filosófica. Para esclarecermos definitivamente a questão em jogo, precisamos definir o individualismo metodológico.
} 
[...] somente trata de partir do comportamento dos homens para descrever determinados processos econômicos" 30 .

A primeira preocupação de Schumpeter ao definir o individualismo metodológico é mostrar como ele se encaixa dentro de sua abordagem descritiva da economia. Isto é, o que interessa quando se usa a hipótese do individualismo metodológico é a descrição do funcionamento de uma economia de troca: "Nós, em geral, não desejamos observar o homem que age, mas somente as quantidades de certos bens que estão em sua posse: desejamos descrever as suas mudanças, ou melhor, um determinado tipo de mudanças, como se elas se verificassem autonomamente, sem dar atenção aos homens que, com efeito, causam-nas" ${ }^{31}$. Observe-se que há uma diferença entre a hipótese do individualismo metodológico, que é central e imutável dentro de toda a economia teórica, e as hipóteses comportamentais. Machlup, quando comenta o individualismo metodológico em Schumpeter, aparentemente não leva em consideração este fato ${ }^{32}$. O individualismo é uma estratégia de modelagem, de engenharia de teoria; contudo, cada edifício teórico pode ter um estrutura distinta e isso está ligado ao tipo de comportamento que o construtor da teoria postula para os indivíduos. O individualismo metodológico não tem relação com o homo oeconomicus do hedonismo, com o homme moyen ou com o ordinary business man marshalliano. É uma hipótese usada para auxiliar a construção da teoria que vê a economia como processo que é resultado da ação de partes isoladas ${ }^{33}$. Dentro da economia teórica estática ${ }^{34}$, o individualismo na teoria aparece com o produtor walrasiano ${ }^{35}$.

\footnotetext{
${ }^{30}$ Schumpeter (1982b:84).

${ }^{31}$ Schumpeter (1982b:80). Schumpeter também irá definir o individualismo metodológico como umaestratégia de modelagem que não leva em consideração o porquê das ações dos indivíduos e irá diferenciar o individualismo metodológico do individualismo sociológico. Ver Schumpeter (1954:888-9).

32 Shionoya (1990:202-3).

33 Schumpeter (1982b:81). Podemos simplesmente dizer que Schumpeter adota uma visão de mundoeconômico atomista e não-holista. Ver Shionoya (1990:202).

${ }^{34}$ Aqui falamos em economia teórica estática pois estamos deixando de lado a dinâmica. A preocupação de Schumpeter é definir o individualismo metodológico dentro do sistema walrasiano, pois em WHT ele não trata da dinâmica. No entanto, pode-se propor uma hipótese de comportamento distinta para o agente econômico, ou pelo menos para alguns deles, quando se constrói uma teoria pura da dinâmica. Neste sentido, o individualismo metodológico continua existindo, mas a hipótese comportamental da estática é distinta da hipótese comportamental da dinâmica. Veremos, no próximo capítulo deste trabalho, esse importante aspecto da epistemologia schumpeteriana da economia teórica, no qual discutiremos o empresário inovador - construção teórica criada por Schumpeter - e o seu papel instrumental dentro da teoria do desenvolvimento econômico.
}

35 O "homem" ou indivíduo que surge nesse contexto é abstrato e absolutamente irreal. Na verdade, este indivíduo pode ser encarado como um locus onde existe uma dada alocação inicial de bens, uma função de valor e um princípio de cálculo "racional" - a maximização. O "agente" nesse sistema não age, não tem vontade, não tem energia; seu comportamento é estritamente reprodutivo, autômato, adaptativo, wishless.

Do ponto de vista epistemológico esse indivíduo é nada mais, nada menos que uma função, utilidade 
Schumpeter, como vimos anteriormente, irá distinguir o individualismo metodológico do individualismo político ${ }^{36}$. Ele salienta que o último possui um conteúdo normativo e até metafísico, enquanto que o primeiro é apenas uma hipótese abstrata. Dada a definição de individualismo metodológico e seu valor estritamente prático-instumental, não cabe mais confundir uma hipótese teórica com um conceito não-econômico como o individualismo político; o primeiro é descritivo, o segundo é prescritivo.

Portanto, também a escolha entre individualismo metodológico e coletivismo metodológico não deve ser determinada por critérios normativos ou pelo valor cognitivo, mas sim por um critério puramente prático-instrumental ${ }^{37}$. Neste ponto Schumpeter é explícito: "Para nós não é tão importante a questão de como tais coisas são na realidade quanto o fato de como devemos esquematizá-las ou estilizar para conseguir, se possível, os nossos objetivos; a nós interessa, em outras palavras, a concessão que seja mais prática do ponto de vista dos resultados da economia pura" ${ }^{38}$

Pode-se dizer, portanto, que uma hipótese será escolhida não se levando em conta o seu valor cognitivo, mas somente o valor prático-instrumental associado à construção da teoria. O individualismo metodológico é escolhido pois encaixa-se perfeitamente numa abordagem da economia como um sistema de trocas entre diversos indivíduos que a compõem e porque abre um atalho na descrição dos fenômenos. A hipótese comportamental - comportamento maximizador do produtor walrasiano - também é escolhida porque gera os resultados descritivos esperados dentro de uma economia em estado estacionário ou semi-estacionário analisada por uma teoria estática. Ainda a respeito desse tema, deve-se notar tam-

associada a um princípio de maximização. Essa modelagem, se não é adequada para explicar endogenamente a mudança dentro do sistema econômico, por outro lado mostra-se útil para descrever uma economia do tipo walrasiana, pois organiza e descrição teórica de uma economia de troca estática e atomizada da forma mais adequada possível. É óbvio que os homens de carne e osso não são autômatos e têm vontade. Porém, à teoria interessa tão-somente uma descrição dos fenômenos e não a sua explicação causal. É dentro desse parâmetro que se relacionam o produtor walrasiano e a hipótese do individualismo metodológico. Poder-se-ia utilizar outro tipo de assunção comportamental dentro da hipótese do individualismo metodológico.

O próprio Schumpeter irá propor, ainda em WHT, a criação de um "homem energético" para a teoria do desenvolvimento econômico - ou dinâmica. Continua valendo a hipótese (ou axioma, no caso) do individualismo metodológico, com a resalva de que o tipo de comportamento do homem energético é distinto do comportamento do produtor walrasiano. A escolha de uma ou de outra hipótese comportamental dependerá do tipo de teoria que eu quero desenvolver — se "estática" ou "dinâmica". Mas é importante sublinhar que o homem ou indivíduo, dentro da economia teórica estática, reduz-se ao produtor walrasiano, que possui um comportamento repetitivo e estritamente adaptativo e a hipótese do individualismo metodológico faz com que o produtor walrasiano seja um conceito abstrato e instrumental, sem valor cognitivo do ponto de vista da economia teórica.

${ }^{36}$ Schumpeter (1982b:84).

${ }^{37}$ A hipótese do individualismo metodológico é escolhida por Schumpeter para a economia teórica, pois enquadra-se com mais eficiência dentro do objetivo da teoria, que é representar uma economia de troca atomizada que gera, como resultado final, um vetor de preços relativos de equilíbrio.

${ }^{38}$ Schumpeter (1982b:86). 
bém que o agente walrasiano, definido dentro do individualismo metodológico schumpeteriano, possui uma racionalidade estritamente instrumental, isto é, o que importa não são os condicionantes reais do comportamento, mas sim a adequação entre meios e fins, medida esta adequação por um princípio de maximização ${ }^{39}$.

\section{CONCLUSÃO}

Schumpeter define uma epistemologia instrumentalista para a economia teórica. É neste sentido que podemos dizer que ele, enquanto economista, é um instrumentalista. As teorias são meros instrumentos que não são falsos, nem verdadeiros; são apenas e tão-somente úteis ou inúteis, eficientes ou não eficientes. Do ponto de vista da escolha entre métodos ou disciplinas de análise, Schumpeter é um pragmático. Quando aparecem problemas que não podem ser tratados exclusivamente pela economia teórica, ele não coloca nenhuma objeção para o uso de outras dis-

\footnotetext{
${ }^{39}$ Cabe fazer uma observação importante aqui. Schumpeter nunca foi muito simpático ao utilitarismo, pois acreditava que ele é prescritivo (normativo) e não descritivo (positivo). No entanto, muitos confundiam a função de valor associada ao indivíduo no mundo walrasiano com uma hipótese utilitarista de caráter filosófico e normativo. Por essa razão, ele sempre advogou a independência entre a teoria marginalista do valor e o utilitarismo. No entanto, a separação entre o utilitarismo e a hipótese do individualismo metodológico só seria totalmente completada, em termos formais e matemáticos, com o advento da teoria da preferência revelada de Samuelson. Nessa teoria não é mais preciso fazer-se qualquer referência à função de utilidade para descrever-se o comportamento dos agentes econômicos: a teoria do comportamento dos agentes individuais reduz-se à sua estrutura puramente lógica e instrumental.
}

Deve-se observar que, curiosamente, o próprio Samuelson - aluno de Schumpeter - identifica a origem do arcabouço epistemológico de sua teoria da escolha no instrumentalismo de Mach. Isto corrobora significativamente a idéia segundo a qual a interpretação que Schumpeter confere ao princípo do valor e ao individualismo metodológico está calcada fundamentalmente numa visão machiana que permeia toda a sua epistemologia. Schumpeter busca uma teoria que seja puro aparato descritivo, um instrumento neutro e frio, sem valor cognitivo, de classificação e arquivamento de fatos com aplicação universal. Samuelson faz, a esse respeito, uma importante afirmação: "Impopulares nestes dias são os pontos de vista de Ernst Mach e dos positivistas lógicos mais rudimentares, que julgam boas as teorias por serem tão-somente descrições econômicas dos fatos complexos e por reproduzirem de forma satisfatória os fatos já observados ou aqueles que ainda estão para ser observados. Não por razões filosóficas, mas por puro resultado da experiência na prática da ciência econômica [economics] [...] encontrei-me entre a minoria que adota a visão machiana. $\mathrm{O}$ 'Entendimento' [Understanding] para a termodinâmica clássica (o arquétipo de um teoria científica bem-sucedida) é entendido por mim como sendo a capacidade de 'descrever' [describe] como os fluidos e sólidos irão de fato comportar-se diante de várias condições especificáveis [...]. Sempre, quando eu tomo contato com novos paradigmas, não-matemáticos e matemáticos, eu tento apreender quais descrições eles geram para os dados observáveis. O paradigma que interessa é aquele cheio de descrições [...]. Meu trabalho sobre preferências reveladas, exposto em Foundations of Economic Analysis, e em muitos volumes do Collected Scientific Papers, consistentemente adota esse procedimento metodológico geral.” Samuelson (1992:242). Ver também Schumpeter (1954:912, no 11, 1056-7), acerca da teoria de Samuelson e da interpretação schumpeteriana do utilitarismo. Sobre essa concepção de racionalidade estritamente instrumental e a sua ligação com a teoria das preferências reveladas, ver Heap (1992:5). Discutimos essa citação de Samuelson no último capítulo deste trabalho. 
ciplinas, tais como a história, a estatística e a sociologia. Escolher-se-á aquela que resolve o problema em questão. Schumpeter afirma que as hipóteses não possuem valor cognitivo; a única função das mesmas é ajudar na construção de uma teoria que se adapte da forma mais econômica possível aos fenômenos. A teoria não explica os fenômenos, mas somente descreve-os, estabelecendo não relações causais, mas sim relações funcionais.

As teorias são estruturas dedutivas. A indução desempenha um papel importante, no entanto, na adaptação das teorias aos fatos, na medida em que se usa a experiência para o aprimoramento das hipóteses mais ordinárias e das teorias. A mudança de hipóteses e teorias não está em função da busca de um maior realismo, mas sim de uma melhor descrição fenomênica, aliada à economia de pensamento. As teorias são constantemente adaptadas aos fatos e o critério de demarcação para Schumpeter, ao modo de Mach, é verificacionista.

Schumpeter tem o seu instrumentalismo derivado principalmente das asserções de Mach, embora receba influências menores de Poincaré e Duhem. Podemos afirmar que o instrumentalismo de Schumpeter é semelhante ao instrumentalismo prépositivismo lógico de Mach. A economia teórica seria pura pois constituir-se-ia numa disciplina com domínio e método próprios. A economia teórica seria exata pois não produz resultados triviais ou dúbios.

\section{REFERÊNCIAS BIBLIOGRÁFICAS}

ALLEN, R.L. Opening Doors: The Life and Work of Joseph Schumpeter (vol.1). Transaction Publishers. (1991a) 1991, primeira edição.

Opening Doors: The Life and Work of Joseph Schumpeter (vol.2). Transaction Publishers. (1991b) 1991, primeira edição.

AUGELLO, M.M. “Works by Schumpeter”. In: The Economics and Sociology of Capitalism, ed. Richard Swedberg. Princeton University Press. 1991.

CHIAPPIN, J.R.N. Duhem's Theory of Science: an Interplay Between Philosophy and History of Science. Tese de Doutorado. University of Pittsburgh. 1989.

CLEMENCE, R.V.(ed.) Essays on Entrepreneurs, Innovations, Business Cycles, and the Evolution of Capitalism. Transaction Publishers. 1989, primeira edição.

DUHEM, P. The Aim and the Structure of Physical Theory. 1981, segunda edição. “Algumas Reflexões Acerca da Física Experimental”. In: Ciência e Filosofia, 4 (1989) (1989a) 87-118.

. "Física e Metafísica”. In: Ciência e Filosofia, 4 (1989) (1989b) 41-59.

HARRIS, S.E.(ed.) Schumpeter: Social Scientist. Harvard University Press. 1951, primeira edição.

HEAP, S. H. (org.). The Theory of Choice. Basil Blackwell. 1992, primeira edição.

MACH, E. Análisis de las Sensaciones. Daniel Jorro Editor. 1925, primeira edição.

. Knowledge and Error. D. Reidel Publishing Company. 1976, quinta edição.

Popular Scientific Lectures. Open Court. 1986, quinta edição.

The Science of Mecanics. Open Court. 1989, quinta edição.

MACHLUP, F. “Schumpeter's Economic Methodology”. In: Schumpeter: Social Scientist, ed. Seymour E.

Harris. Havard University Press. 1951.

POINCARÉ, H. Science and Hypotesis. Dover Publications Inc. 1952, primeira edição. . La Valeur de la Science. Ernest Flammarion, Éditeur. 1913, primeira edição. 
SAMUELSON, P.A. “My Life Philosophy: Policy Credos and Working Ways”. In: Eminent Economists: Their Life Philosophies, ed. Szenberg, M. Cambridge University Press. 1992, primeira edição. "Schumpeter as a Teacher and economic Theorist". In: Schumpeter: Social Scientist, ed. Seymour E. H. Harvard University Press. 1951.

SCHNEIDER, E. “Schumpeter's Early German Work”. In: Schumpeter: Social Scientist, ed. Seymour Harris. Harvard University Press. 1951.

SCHUMPETER, J.A. Business Cycles: A Theoretical, Historical, and Statistical Analysis of the Capitalist Process. MacGraw-Hill Book Company, Inc. 1939, primeira edição. Capitalism, Socialism and Democracy. Harper \& Row. 1950, terceira edição.

"The Common Sense of Econometrics". In: Essays on Entrepreneurs, Innovations, Business Cycles, and the Evolution of Capitalism. ed. R.V. Clemence.Transaction Publishers. (1989a) 1989. . "The Concept of Social Value". In: Essays on Entrepreneurs, Innovations, Business Cycles, and the Evolution of Capitalism. ed. R.V.Clemence. Transaction Publishers. (1989b) 1989.

. "The 'Crisis' in Economics (Fifty Years Ago). In: Journal of Economic Literature, (1982a), 20 (1982) 1049-1059.

Economic Doctrine and Method: an Historical Sketch. George Allen \& Unwin LTD. 1954, primeira edição.

L'Essenza e i Principi dell' Economia Teorica. Laterza. (1982b) 1982, primeira edição.

. "The Explanation of the Business Cycle". In: Essays on Entrepreneurs, Innovations, Business Cycles, and the Evolution of Capitalism. ed. R.V. Clemence. Transaction Publishers. (1989c) 1989.

. "The Historical Approach to the Analysis of Business Cycles". In: Essays on Entrepreneurs, Innovations, Business Cycles, and the Evolution of Capitalism. ed. R.V. Clemence. Transaction Publishers. (1989d) 1989.

. History of Economic Analysis. Oxford University Press. 1954, primeira edição.

"Max Weber Work". In: The Economics and Sociology of Capitalism, ed. Richard Swedberg. Princeton University Press. (1991a) 1991.

"The Meaning of Rationality in the Social Sciences". In: The Economics and Sociology of Capitalism. ed. Richard Swedberg. Princeton University Press. (1991b) 1991.

"Preface to Japonese Edition of 'Theorie der Wirtschaftlichen Entwicklung”". In: Essays on Entrepreneurs, Innovations, Business Cycles, and the Evolution of Capitalism. ed. R.V. Clemence. Transaction Publishers. (1989e) 1989.

Ten Great Economists: from Marx to Keynes. George Allen \& Unwin LTD.1956, primeira edição.

"Theoretical Problems of Economic Growth". In: Essays on Entrepreneurs, Innovation, Business Cycles, and the Evolution of Capitalism. ed. R.V. Clemence.Transaction Publishres. (1989f) 1989.

The Theory of Economic Development: an Inquiry into Profits, Capital, Credit, Interest, and he Business Cycle. Harvard University Press. 1955, segunda edição.

"Recent Developments of Political Economy". In: The Economics and Sociology of Capitalism, ed. Richard Swedberg. Princeton University Press. (1991c) 1991.

"Science and Ideology". In: The American Economic Review, 39:2 (1949) 345-359.

"Some Questions of Principle". In: Research in the History of Economic Thought and Methodology, 5 (1987) 93-116.

SHIONOYA, Y. Shumpeter and the Idea of Social Science. Cambridge University Press. 1997, primeira edição.

SHIONOYA, Y. “Instrumentalism in Schumpeter's Economic Methodology”. In: History of Political Economy, 22:2 (1990) 187-221.

SILVA, M.F. A Epistemologia da Economia em Schumpeter: Uma Investigação sobre o Instrumentalismo. IPE, FEA, Universidade de São Paulo. Tese de Doutorado, 1994.

STARK, W. "Joseph Schumpeters Umwertung der Werte: Eine kritische Auseinandersetzung mit seiner History of economic Analysis”. In: Kyklos, 7 (1955) 225-251. 
STUMP, D. "Henri Poincaré's Philosophy of Science”. In: Studies in History and Philosophy of Science, 20 (1989) 335-363.

SWEDBERG, R. The Economics and Sociology of Capitalism. Princenton University Press. (1991a) 1991, primeira edição. "Introduction". In: The Economics and Sociology of Capitalism, ed. Richard Swedberg. Princeton University Press.(1991a) 1991. . Joseph A. Schumpeter: His Life and Work. Polity Press. (1991b) 1991, primeira edição. "Schumpeter's Early Work". In: Journal of Evolucionary Economics, 2:(1) (1992) 69-82. TOULMIN. S. \& JANIK, A. La Viena de Wittgenstein. Taurus. 1983, primeira edição. 